\title{
Diabetes education and self-care behaviors in patients with diabetes in Mexico
}

\section{Educación en diabetes y comportamientos del autocuidado en pacientes con diabetes en México}

\author{
Alonso Romo-Romo ${ }^{1}$, Donají V. Gómez-Velasco ${ }^{2}$, Gabriela A. Galán-Ramírez ${ }^{2}$, Marcela Janka-Zires ${ }^{1}$, \\ Griselda X. Brito-Córdova ${ }^{1}$, Lizeth Gómez-Munguía ${ }^{2}$, Ana L. Sarmiento-Moreno ${ }^{1}$,

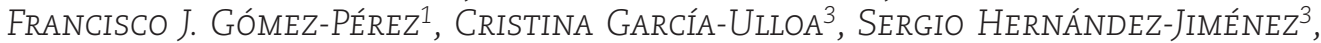 \\ Carlos A. Aguilar-Salinas ${ }^{2,4}$, and Paloma Almeda-Valdes ${ }^{1,2 *}$
}

${ }^{1}$ Department of Endocrinology and Metabolism; ${ }^{2}$ Research Unit of Metabolic Diseases; ${ }^{3}$ Center for Comprehensive Care for the Patient with Diabetes; ${ }^{4}$ Division of Nutrition. Instituto Nacional de Ciencias Médicas y Nutrición Salvador Zubirán, Mexico City, Mexico

\begin{abstract}
Background: Diabetes educators are an important element in the multidisciplinary treatment team of diabetes. Diabetes education interventions are recommended throughout the course of the disease since they have a favorable impact in glucose control. Objective: The objective of the study was to evaluate the baseline status and at follow-up of patients participating in diabetes education sessions. Methods: Retrospective cohort study based on the review of clinical records of patients from a National Health Institute in Mexico. A total of 153 subjects that attended individual sessions were included in the study. Changes were assessed in 48 participants that had a second evaluation. The outcomes included clinical, anthropometric, and biochemical parameters, along with variables related to diabetes education. Results: The knowledge about tools for diabetes self-management was poor. Significant changes were found in different components that promote self-management of diabetes including knowing glycemic targets, performing an adequate insulin injection, and practicing self-monitoring of blood glucose. Conclusions: The knowledge of patients with diabetes about their disease is inadequate. Interventions related to diabetes education could promote better adherence to self-care behaviors in patients with diabetes.
\end{abstract}

Key words: Diabetes mellitus. Health education. Public assistance. Blood glucose self-monitoring. Hypoglycemia.

\begin{abstract}
RESUMEN
Introducción: Los educadores en diabetes son un elemento importante en el equipo multidisciplinario para el tratamiento de la diabetes. Las intervenciones de educación en diabetes se recomiendan a lo largo de la enfermedad debido a que tienen un impacto favorable en el control glucémico. Objetivo: Evaluar el estado basal y al seguimiento de pacientes que participaron en sesiones sobre educación en diabetes. Métodos: Cohorte retrospectiva basada en revisión de expedientes clínicos de pacientes de un Instituto Nacional de Salud en México. Fueron incluidos en el estudio 153 individuos que recibieron sesiones individuales. Se analizaron cambios en 48 participantes que tuvieron una segunda evaluación. Los desenlaces incluyeron parámetros clínicos, antropométricos y bioquímicos, junto con variables relacionadas con educación en diabetes. Resultados: El conocimiento acerca de las herramientas para el autocuidado en diabetes es pobre. Se encontraron cambios significativos en diferentes componentes que promueven el autocuidado en diabetes, incluyendo conocer las metas de control glucémico, realizar una técnica correcta de aplicación de insulina y practicar automonitoreo de glucosa. Conclusiones: El conocimiento en pacientes con diabetes en México es inadecuado. Intervenciones de educación en diabetes podrían promover mayor adherencia a conductas de autocuidado.
\end{abstract}

Palabras clave: Diabetes mellitus. Educación en salud. Asistencia pública. Automonitoreo de glucosa. Hipoglucemia.
Correspondence:

*Paloma Almeda-Valdes

E-mail: paloma.almedav@incmnsz.mx
Date of reception: 17-11-2020

Date of acceptance: 18-02-2021

DOI: 10.24875/RME.20000115
Available online: 02-11-2021

Rev Mex Endocrinol Metab Nutr. 2021;8:183-91

2462-4144 / ๔ 2021 Sociedad Mexicana de Nutrición y Endocrinología, AC. Published by Permanyer. This is an open access article under the terms of the CC BY-NC-ND license (http://creativecommons.org/licenses/by-nc-nd/4.0/). 


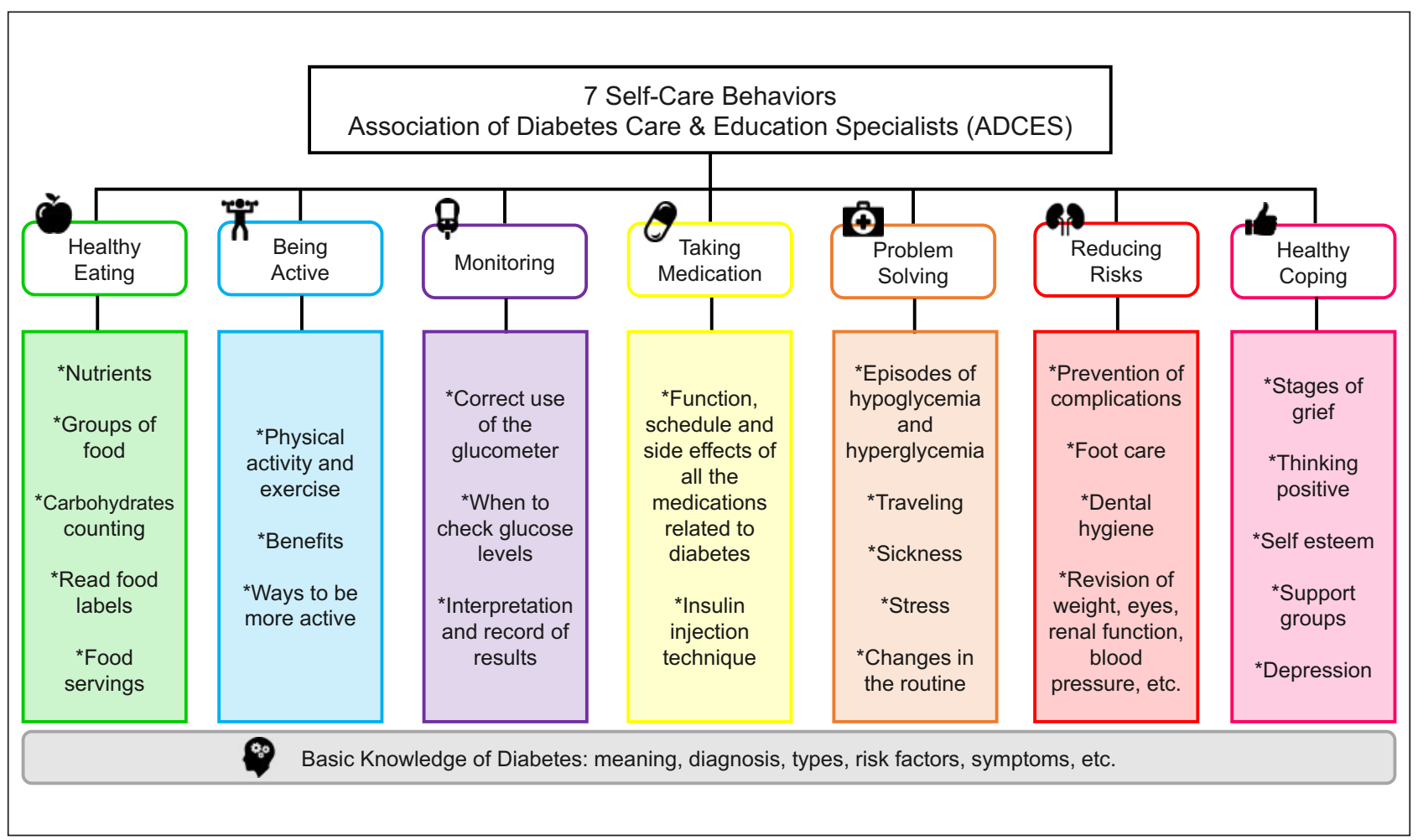

Figure 1. Description of each of the seven self-care behaviors of diabetes along with basic knowledge about diabetes in accordance to the Association of Diabetes Care and Education Specialists.

\section{INTRODUCTION}

Diabetes education is a process in which patients with diabetes acquire knowledge and skills to change behaviors and are empowered in the selfmanagement with the aim of improving glucose control and preventing complications ${ }^{1}$. The diabetes educator is an essential member within the multidisciplinary team to treat diabetes ${ }^{2,3}$. Any health professional that has been trained in the seven self-care behaviors of diabetes (Fig. 1) established by the American Association of Diabetes Educators, currently named Association of Diabetes Care and Education Specialists can be a diabetes educator ${ }^{4}$. Diabetes education emerged before the discovering of insulin, when malnutrition in people with diabetes was common because due to periods of fasting to avoid ketoacidosis and glycosuria. Nurses in charge of the "starvation therapy" began to specialize in diabetes and took a role in education ${ }^{5}$. Frederick Banting and Charles Best, in collaboration with John Macleod, isolated and extracted insulin in $1921^{6}$. In 1923, when insulin became available for use, the need of health professionals to teach patients to administer insulin, count carbohydrates, and monitor glycosuria turned into a priority. Later, Dr. Elliot Proctor Joslin recognized the importance of educating nurses in diabetes and became a pioneer in the training of certified diabetes educators ${ }^{5}$. The American Diabetes Association highlights that diabetes self-management education and support are relevant to prevent or delay type 2 diabetes, as well as to facilitate knowledge and informed decision-making in diabetes ${ }^{7}$. Diabetes education promotes lowers glycated hemoglobin ( $\mathrm{HbA1c}$ ), improves quality of life, reduces all-cause mortality risk, and diminishes health-care costs ${ }^{8-12}$. The aim of this study is to describe some aspects of the knowledge about self-care behaviors in patients that assisted to diabetes education sessions in a National Health Institute in Mexico and to compare the changes in a subset that attended a second evaluation. 


\section{MATERIALS AND METHODS}

\section{Description of participants}

Participants included in the study attended individual sessions concerning diabetes education at the Instituto Nacional de Ciencias Médicas y Nutrición Salvador Zubirán. The criteria to participate in the sessions include any type of diabetes, age $\geq 18$ years, and one or more of the following: (1) $\mathrm{HbA} 1 \mathrm{c} \geq 8.5 \%$, (2) problems with the insulin injection technique, or (3) recurrent hypoglycemia.

\section{Study design}

This was a retrospective cohort study. Data from the electronic database of the clinical files of participants were evaluated from June 2017 to December 2018. Patients who had most of the data for the study were included in the analysis $(n=153)$. Changes at follow-up were evaluated in 48 subjects that had a second evaluation.

\section{Outcomes}

Sociodemographic data included sex, age, and education level. Clinical variables considered were type of diabetes, disease duration, hypertension, smoking habit, exercise, blood pressure, and heart rate. Other variables obtained were hypoglycemia-induced falls, episodes of severe hypoglycemia, and hospitalizations due to hypoglycemia or hyperglycemia. Anthropometric measurements recorded were weight, height, and waist circumference. Body mass index (BMI) was calculated and classified (normal weight, overweight, and obesity) according to the World Health Organization. Abdominal obesity was established using the cutoff values established by the International Diabetes Federation for Latin Americans (waist circumference $\geq 80 \mathrm{~cm}$ in women or $\geq 90 \mathrm{~cm}$ in men). Biochemical parameters included fasting glucose, HbA1c, total cholesterol, lowdensity lipoprotein (LDL) cholesterol, high-density lipoprotein (HDL) cholesterol, triglycerides, creatinine, and urinary albumin-to-creatinine ratio. These analyses were performed $<1$ month before the consultation. A capillary glucose concentration was measured during the consultation and was classified in three categories: (1) at fasting, (2) post-prandial $<2 \mathrm{~h}$, and (3) post-prandial $\geq 2 \mathrm{~h}$. Reasons for consultation were grouped in five categories: (1) glycemic control, (2) insulin application, (3) recurrent hypoglycemia, (4) glucometer use, and (5) carbohydrate counting. Variables related to diabetes education included knowledge of pre-prandial and post-prandial glycemic targets and glucose concentration to define hypoglycemia ${ }^{13}$. This information was classified in three categories: (1) does not know, (2) correct answer, and (3) incorrect answer. Insulin application was classified in four categories: (1) not required, (2) starts using insulin, (3) correct technique, and (4) incorrect technique. Self-monitoring of blood glucose (SMBG) was classified in four categories: (1) does not perform, (2) adequate ( $\geq 2$ times/ week) and make changes in case of hypoglycemia or hyperglycemia, (3) adequate but does not make changes, and (4) inadequate. Sick days were classified into three categories: (1) did not present, (2) presented and performed actions (sufficient hydration, increased SMBG, and continuing diabetes medications), and (3) presented and did not perform actions. Finally, hypoglycemia was classified in five categories: (1) did not presented, (2) pseudohypoglycemia (symptoms but glucose concentration $\geq 70$ $\mathrm{mg} / \mathrm{dL}$ ), (3) probable symptomatic hypoglycemia (glucose concentration not documented), (4) asymptomatic hypoglycemia documented, and (5) symptomatic hypoglycemia documented.

\section{Description of procedures}

The health professionals that provided the sessions were endocrinologists and dietitians certified as diabetes educators. The consultations were given individually, and the topics addressed in each session related to any of the self-care behaviors of diabetes (Fig. 1) in addition to the basic knowledge about diabetes, giving priority to the main problem for which the patient was referred. The duration of each consultation was approximately 45-60 min. The time between subsequent visits varied depending on the demand of the agenda and attendance 
of patients. The instruments used included a SECA mechanical weight scale with height rod model 700, a Lufkin Executive Thinline diameter pocket tape measure $(6 \mathrm{~mm} \times 2 \mathrm{~m})$ model W606PM, an Omron automatic digital blood pressure monitor model HEM-781INT, and a blood glucose meter FreeStyle model Optium Neo by Abbott Diabetes Care Ltd.

\section{Statistical analysis}

Variables distribution was evaluated with Kolmogorov-Smirnov normality test. Descriptive characteristics of the study population are reported as means \pm standard deviations, medians (interquartile ranges) or frequencies, and percentages according to the nature and distribution. Changes in the participants subset that attended a second session were evaluated with paired t-test or Wilcoxon matched pairs test, as appropriate. Changes in categorical dichotomous variables were evaluated with McNemar's test and polychotomous variables with the extension McNemar-Bowker test. Data were analyzed using the IBM SPSS Statistics version 25.0 software. $p<0.05$ was considered statistically significant.

\section{RESULTS}

Our population ( $n=153$ ) consisted mostly of women (68\%) with an age of $54.8 \pm 15.8$ years. Most of the participants had type 2 diabetes $(74.5 \%)$ and 84 subjects had hypertension (54.9\%). More than half of participants (58.9\%) practiced exercise, mainly aerobic, 5 days/week with a duration of 40 min per session. Reported hospitalizations were more frequent due to hyperglycemia versus hypoglycemia (19.0\% vs. $5.2 \%)$. The sociodemographic and clinical variables are described in table 1 . The BMI was $27.6 \pm 4.7 \mathrm{~kg} / \mathrm{m}^{2}$ and $69.3 \%$ of the population had overweight or obesity, along with a prevalence of $77.1 \%$ of abdominal obesity. Most of the participants were out of targets for glycemic control, with a median fasting glucose of $172 \mathrm{mg} / \mathrm{dL}$ and $\mathrm{HbA} 1 \mathrm{c}$ of $9.3 \%$. Anthropometric and biochemical parameters are shown in table 2 .
Table 1. Description of sociodemographic and clinical characteristics of the study population

\begin{tabular}{|c|c|}
\hline & $\mathrm{n}=153$ \\
\hline Sex: women, n (\%) & $104(68.0 \%)$ \\
\hline Age (years) & $54.8 \pm 15.8$ \\
\hline \multicolumn{2}{|l|}{ Education level, n (\%) } \\
\hline None & $21(13.7 \%)$ \\
\hline Primary school & $23(15.0 \%)$ \\
\hline Secondary school & $28(18.3 \%)$ \\
\hline Higher education & $22(14.4 \%)$ \\
\hline Technical career & $14(9.2 \%)$ \\
\hline College & $39(25.5 \%)$ \\
\hline Postgraduate & $6(3.9 \%)$ \\
\hline \multicolumn{2}{|l|}{ Type of diabetes, n (\%) } \\
\hline Type 1 diabetes & $30(19.6 \%)$ \\
\hline Type 2 diabetes & $114(74.5 \%)$ \\
\hline Other specific types of diabetes & $9(5.9 \%)$ \\
\hline Disease duration (years) & $15(8-23)$ \\
\hline Diagnosis of hypertension, $\mathrm{n}(\%)$ & $84(54.9 \%)$ \\
\hline Smoking habit, $n(\%),(n=90)^{*}$ & $10(11.1 \%)$ \\
\hline \multicolumn{2}{|l|}{ Exercise, $n(\%),(n=90)^{*}$} \\
\hline Yes & $53(58.9 \%)$ \\
\hline Aerobic & $51(96.2 \%)$ \\
\hline Anaerobic & $2(3.8 \%)$ \\
\hline Days per week & $5(3-5.5)$ \\
\hline Minutes per training & $40(30-60)$ \\
\hline Systolic blood pressure (mmHg) & $127(112-142)$ \\
\hline Diastolic blood pressure $(\mathrm{mmHg})$ & $79(70-85)$ \\
\hline Heart rate (bpm) & $74(68-84)$ \\
\hline Hypoglycemia-induced fall events, n (\%) & $14(9.2 \%)$ \\
\hline Episodes of severe hypoglycemia, n (\%) & $25(16.3 \%)$ \\
\hline Hospitalizations due to hypoglycemia, n (\%) & $8(5.2 \%)$ \\
\hline Hospitalizations due to hyperglycemia, n (\%) & $29(19.0 \%)$ \\
\hline \multicolumn{2}{|c|}{$\begin{array}{l}\text { Quantitative variables are expressed in means } \pm \text { standard deviations or } \\
\text { medians (interquartile ranges) according to the data distribution. Categorical } \\
\text { variables are described in frequencies and percentages. } \\
{ }^{*} \text { Data were not available in the total of the population. }\end{array}$} \\
\hline \multicolumn{2}{|c|}{$\begin{array}{l}\text { The main reason to be referred to the diabetes edu- } \\
\text { cation sessions was poor glycemic control ( } 56.9 \%) \text {, } \\
\text { followed by problems with the insulin injection te- } \\
\text { chnique }(22.2 \%) \text {. A low proportion of participants } \\
\text { knew the correct pre-prandial and post-prandial } \\
\text { glucose target ( } 8.5 \% \text { and } 19.0 \% \text {, respectively), and } \\
\text { approximately seven out of } 10 \text { participants did not } \\
\text { know the glucose concentration to define hypo- } \\
\text { glycemia. About } 30 \% \text { of the population was going } \\
\text { to start insulin application, } 22.3 \% \text { carried out an }\end{array}$} \\
\hline
\end{tabular}


Table 2. Description of anthropometric and biochemical characteristics of the study population

\begin{tabular}{lc}
\hline & $\mathrm{n}=153$ \\
\hline Weight $(\mathrm{kg})$ & $68.0 \pm 14.1$ \\
\hline Height $(\mathrm{cm})$ & $156.8 \pm 1.0$ \\
\hline Body mass index $\left(\mathrm{kg} / \mathrm{m}^{2}\right)$ & $27.6 \pm 4.7$ \\
\hline Category of body mass index, $\mathrm{n}(\%)$ & $47(30.7 \%)$ \\
\hline Normal weight & $62(40.5 \%)$ \\
\hline Overweight & $44(28.8 \%)$ \\
\hline Obesity & $90.7 \pm 12.7$ \\
\hline Waist circumference $(\mathrm{cm})$ & $96.3 \pm 13.8$ \\
\hline Women & $118(77.1 \%)$ \\
\hline Men & $172(109-251)$ \\
\hline Abdominal obesity, $\mathrm{n}(\%)$ & $9.3(7.9-10.7)$ \\
\hline Fasting glucose $(\mathrm{mg} / \mathrm{dL})$ & $175(145-210)$ \\
\hline HbA1c $(\%)$ & $101(77-130)$ \\
\hline Total cholesterol $(\mathrm{mg} / \mathrm{dL})$ & $49(40-56)$ \\
\hline LDL cholesterol $(\mathrm{mg} / \mathrm{dL})$ & $136(97-194)$ \\
\hline HDL cholesterol $(\mathrm{mg} / \mathrm{dL})$ & $0.76(0.63-0.97)$ \\
\hline Triglycerides $(\mathrm{mg} / \mathrm{dL})$ & $20.3(5.6-121.0)$ \\
\hline Creatinine $(\mathrm{mg} / \mathrm{dL})$ & $163(118-257)$ \\
\hline Urinary albumin-to-creatinine ratio $(\mathrm{mg} / \mathrm{g})$ & $280(173-393)$ \\
\hline Capillary glucose concentration $(\mathrm{mg} / \mathrm{dL})$ & $(130-217)$ \\
\hline Fasting & \\
\hline Post-prandial $<2 \mathrm{~h}$ & \\
\hline Post-prandial $\geq 2 \mathrm{~h}$ & \\
\hline
\end{tabular}

Quantitative variables are expressed in means \pm standard deviations or medians (interquartile ranges) according to the data distribution. Categorical variables are described in frequencies and percentages. HbA1c: glycated hemoglobin; LDL: low-density lipoprotein; HDL: high-density lipoprotein.

adequate insulin injection, and $18.4 \%$ were performing an inadequate application. Almost half of the participants (48.5\%) did not perform SMBG or the frequency was low and most of the participants that practiced it, did not make changes with the results obtained. Of the 24 participants that presented sick days, only 11 performed correctly necessary actions during these days. In addition, only $16.5 \%$ had documented recent hypoglycemia (asymptomatic or symptomatic) and $16.3 \%$ had history of at least one episode of severe hypoglycemia. The description of variables related to diabetes education is presented in table 3.

The time between the first and second evaluation in the 48 subjects with a subsequent session was $25 \pm 8.2$ weeks (minimum 8 and maximum 55 weeks).
Table 3. Description of diabetes education variables of the study population

$$
\mathrm{n}=153
$$

Reason for consultation, $\mathrm{n}(\%)$

\begin{tabular}{|c|c|}
\hline Glycemic control & $87(56.9 \%)$ \\
\hline Insulin application & $34(22.2 \%)$ \\
\hline Recurrent hypoglycemia & $14(9.2 \%)$ \\
\hline Glucometer use & $10(6.5 \%)$ \\
\hline Carbohydrates counting & $8(5.2 \%)$ \\
\hline \multicolumn{2}{|l|}{ Pre-prandial glycemic target, n (\%) } \\
\hline Does not know & $46(30.1 \%)$ \\
\hline Correct answer & $13(8.5 \%)$ \\
\hline Incorrect answer & $94(61.4 \%)$ \\
\hline \multicolumn{2}{|l|}{ Post-prandial glycemic target, n (\%) } \\
\hline Does not know & $79(51.6 \%)$ \\
\hline Correct answer & $29(19.0 \%)$ \\
\hline Incorrect answer & $45(29.4 \%)$ \\
\hline \multicolumn{2}{|c|}{ Value to define hypoglycemia, $n(\%),(n=134)^{*}$} \\
\hline Does not know & $56(41.8 \%)$ \\
\hline Correct answer & $33(24.6 \%)$ \\
\hline Incorrect answer & $45(33.6 \%)$ \\
\hline \multicolumn{2}{|l|}{ Insulin application, $\mathrm{n}(\%),(\mathrm{n}=103)^{*}$} \\
\hline Not required & $29(28.2 \%)$ \\
\hline Starts using insulin & $32(31.1 \%)$ \\
\hline Correct technique & $23(22.3 \%)$ \\
\hline Incorrect technique & $19(18.4 \%)$ \\
\hline \multicolumn{2}{|c|}{ Self-monitoring of blood glucose, $n(\%),(n=103)^{*}$} \\
\hline Does not practice & $37(35.9 \%)$ \\
\hline Adequate and make changes & $24(23.3 \%)$ \\
\hline Adequate but does not make changes & $29(28.2 \%)$ \\
\hline Inadequate & $13(12.6 \%)$ \\
\hline \multicolumn{2}{|l|}{ Sick days, $n(\%),(n=103)^{*}$} \\
\hline Did not presented & $79(76.7 \%)$ \\
\hline Presented and performs actions & $11(10.7 \%)$ \\
\hline Presented and does not performs actions & $13(12.6 \%)$ \\
\hline \multicolumn{2}{|l|}{ Hypoglycemia, $n(\%),(n=103)^{*}$} \\
\hline Did not presented & $72(69.9 \%)$ \\
\hline Pseudohypoglycemia & $4(3.9 \%)$ \\
\hline Probable symptomatic hypoglycemia & $10(9.7 \%)$ \\
\hline $\begin{array}{l}\text { Asymptomatic hypoglycemia } \\
\text { documented }\end{array}$ & $5(4.8 \%)$ \\
\hline Symptomatic hypoglycemia documented & (11.7\%) \\
\hline
\end{tabular}

Data are presented in frequencies and percentages.

${ }^{*}$ Data were not available in the total of the population.

Anthropometric parameters (weight, BMl, and waist circumference) remained unchanged; however, there was a tendency to a significant reduction in the systolic blood pressure $(p=0.05)$. A slight and almost 


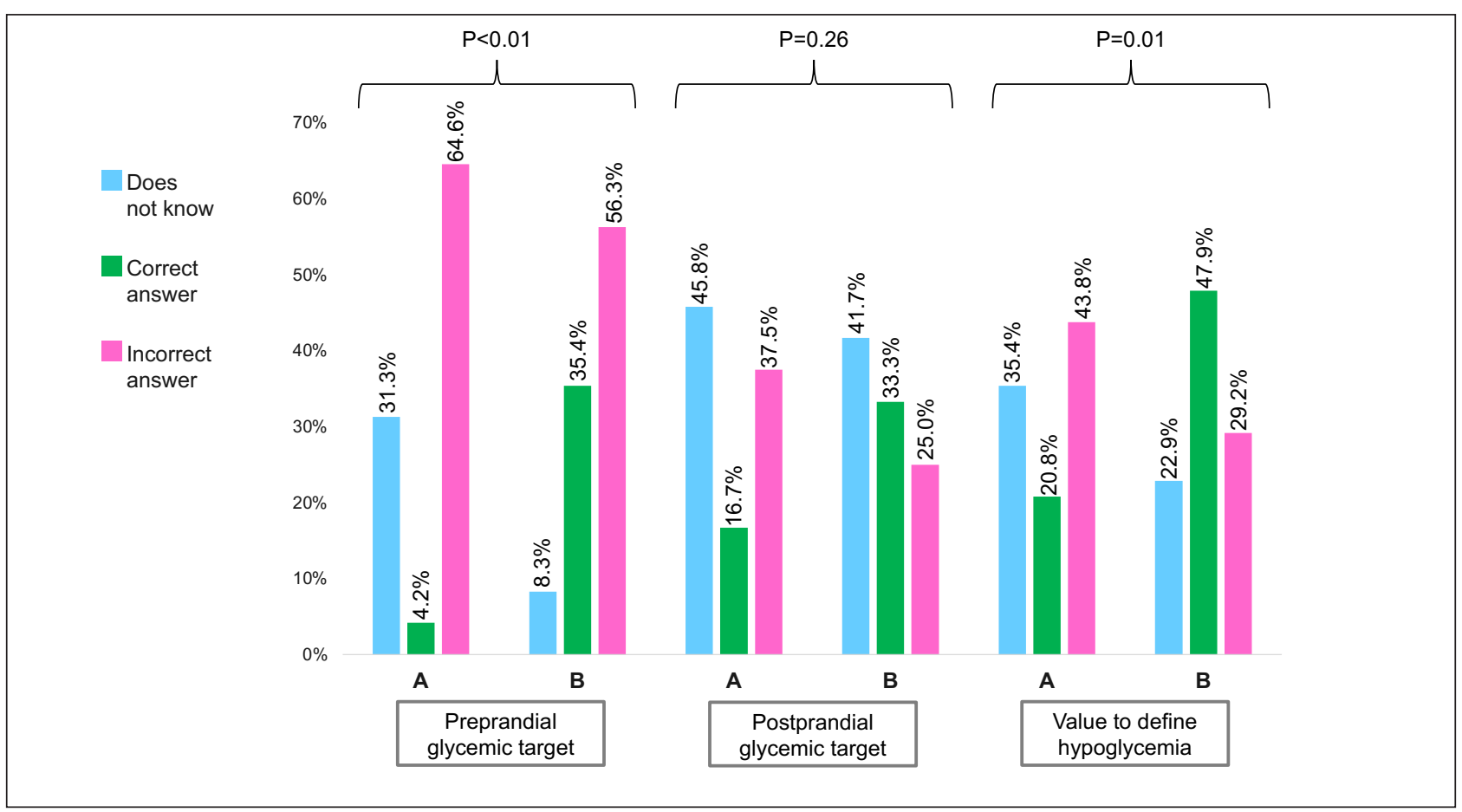

Figure 2. Changes in the knowledge of glycemic targets and the glucose concentration to define hypoglycemia in the participants that attended a second education session. Data are expressed in percentages and differences ( $p$ value) were evaluated with McNemar-Bowker test, (A) the first evaluation and (B) the second evaluation of each variable.

significant decrease in the $\mathrm{HbA1c}(\mathrm{p}=0.06)$ was observed (delta $-0.31 \pm 1.0 \%$ [95\% confidence interval (Cl): $-0.64,0.01])$. A reduction in total, $L D L$, and HDL cholesterol $(p<0.05)$ was observed. The capillary glucose concentration at fasting and post-prandial $<2 \mathrm{~h}$ measured during the consultation showed a significant reduction between evaluations $(p<0.01)$. Figure 2 shows the changes in the knowledge about the pre-prandial glycemic target, post-prandial glycemic target, and the value to define hypoglycemia; the proportion of a correct answer increased from 4.2\% to $35.4 \%(p<0.01)$, from $16.7 \%$ to $33.3 \%(p=0.26)$, and from $20.8 \%$ to $47.9 \%(p=0.01)$, respectively. The prevalence of patients injecting insulin with an adequate technique increased from $16.7 \%$ to $45.8 \%$ $(p<0.01)$. A reduction of the participants who did not perform the SMBG was observed (from 31.3\% to $12.5 \%)$, along with an increase in the proportion (from $14.7 \%$ to $50.0 \%$ ) of participants performing an adequate SMBG and making actions according to the values obtained $(p<0.01)$. There was a tendency $(p=0.13)$ to a significant increase in performing correct actions during sick days ( $8.3 \%$ vs. $16.7 \%)$. Finally, a non-significant reduction in the episodes of severe hypoglycemia and hospitalizations due to hyperglycemia was observed $(p=0.10$ and $p=0.06$, respectively). The changes between evaluations are reported in table 4.

\section{DISCUSSION}

This report shows that subjects that attended individual diabetes education sessions have poor knowledge about diabetes self-management. Positive changes in components that promote self-management of diabetes were found in the subset of individuals with a follow-up visit.

Nowadays, medical nutrition therapy, mental health, diabetes self-management education, and support are recognized as elementary components of the integral treatment of diabetes to improve patient care, reduce the risk of developing complications and health-care costs. It is advisable to provide diabetes 
Table 4. Changes in different variables in a subset of the study population who attended a second diabetes education session $(n=48)$

\begin{tabular}{|c|c|c|c|}
\hline & First evaluation & Second evaluation & $\mathrm{P}$ \\
\hline Weight (kg) & $68.3 \pm 13.6$ & $68.0 \pm 13.5$ & $0.58^{a}$ \\
\hline Body mass index $\left(\mathrm{kg} / \mathrm{m}^{2}\right)$ & $27.7 \pm 4.0$ & $27.0 \pm 3.8$ & $0.56^{a}$ \\
\hline Waist circumference $(\mathrm{cm})$ & $92.6 \pm 12.7$ & $92.0 \pm 10.4$ & $0.61^{a}$ \\
\hline Systolic blood pressure (mmHg) & $133.5 \pm 22.1$ & $127.2 \pm 21.5$ & $0.05^{a}$ \\
\hline Diastolic blood pressure $(\mathrm{mmHg})$ & $78.9 \pm 12.6$ & $76.9 \pm 12.8$ & $0.25^{\mathrm{a}}$ \\
\hline Heart rate $(\mathrm{bpm})$ & $76.5 \pm 10.3$ & $74.9 \pm 10.8$ & $0.39^{a}$ \\
\hline Fasting glucose (mg/dL) & $149(101-229)$ & $140(110-198)$ & $0.20^{b}$ \\
\hline $\mathrm{HbA1c}(\%)$ & $9.3 \pm 1.7$ & $9.0 \pm 1.7$ & $0.06^{a}$ \\
\hline Total cholesterol (mg/dL) & $178(150-208)$ & $155(136-195)$ & $0.04^{b}$ \\
\hline LDL cholesterol (mg/dL) & $107(82-131)$ & $86(65-122)$ & $0.01^{b}$ \\
\hline HDL cholesterol (mg/dL) & $49(37-55)$ & $43(38-49)$ & $0.04^{b}$ \\
\hline Triglycerides (mg/dL) & $143(98-207)$ & $138(95-183)$ & $0.21^{b}$ \\
\hline Creatinine $(\mathrm{mg} / \mathrm{dL})$ & $0.77(0.60-1.08)$ & $0.78(0.60-1.10)$ & $0.68^{b}$ \\
\hline Urinary albumin-to-creatinine ratio (mg/g) & $24.8(7.7-93.8)$ & $15.5(5.1-90.2)$ & $0.90^{b}$ \\
\hline \multicolumn{4}{|l|}{ Capillary glucose concentration (mg/dL) } \\
\hline Fasting & $212.2 \pm 98.4$ & $153.1 \pm 51.0$ & $<0.01^{a}$ \\
\hline Post-prandial $<2 \mathrm{~h}$ & $286.3 \pm 101.1$ & $193.5 \pm 75.1$ & $<0.01^{a}$ \\
\hline Post-prandial $\geq 2 \mathrm{~h}$ & $198.0 \pm 110.2$ & $195.0 \pm 56.8$ & $0.92^{a}$ \\
\hline \multicolumn{4}{|l|}{ Insulin application } \\
\hline Not required & $19(39.6 \%)$ & $14(29.2 \%)$ & $<0.01^{c}$ \\
\hline Starts using insulin & $11(22.9 \%)$ & $5(10.4 \%)$ & \\
\hline Correct technique & $8(16.7 \%)$ & $22(45.8 \%)$ & \\
\hline Incorrect technique & $10(20.8 \%)$ & $7(14.6 \%)$ & \\
\hline \multicolumn{4}{|l|}{ Self-monitoring of blood glucose } \\
\hline Does not practice & $15(31.3 \%)$ & $6(12.5 \%)$ & $<0.01^{c}$ \\
\hline Adequate and make changes & $7(14.7 \%)$ & $24(50.0 \%)$ & \\
\hline Adequate but does not make changes & $16(33.3 \%)$ & $16(33.3 \%)$ & \\
\hline Inadequate & $10(20.8 \%)$ & $2(4.2 \%)$ & \\
\hline \multicolumn{4}{|l|}{ Sick days } \\
\hline Did not presented & $33(68.8 \%)$ & $37(77.1 \%)$ & $0.13^{c}$ \\
\hline Presented and performs actions & $4(8.3 \%)$ & $8(16.7 \%)$ & \\
\hline Presented and does not performs actions & $11(22.9 \%)$ & $3(6.3 \%)$ & \\
\hline Hypoglycemia-induced fall events, n (\%) & $6(12.5 \%)$ & $3(6.3 \%)$ & $0.37^{d}$ \\
\hline Episodes of severe hypoglycemia, n (\%) & $9(18.8 \%)$ & $3(6.3 \%)$ & $0.10^{d}$ \\
\hline Hospitalizations due to hypoglycemia, n (\%) & $3(6.3 \%)$ & $2(4.2 \%)$ & $1.00^{d}$ \\
\hline Hospitalizations due to hyperglycemia, n (\%) & $9(18.8 \%)$ & $2(4.2 \%)$ & $0.06^{d}$ \\
\hline
\end{tabular}

Quantitative variables are expressed in means \pm standard deviations or medians (interquartile ranges) according to the data distribution. Categorical variables are described in frequencies and percentages. HbA1c: glycated hemoglobin; LDL: low-density lipoprotein; HDL: high-density lipoprotein.

apaired $t$ test, ${ }^{b}$ Wilcoxon matched-pairs test, cMcNemar-Bowker test, 'McNemar's test.

education interventions at diagnosis with at least an annual assessment, when complicating factors impacting self-management appear and when transitions in care occur ${ }^{14}$. Despite this, not all health systems give sufficient importance to diabetes education, or it is not possible to provide a multidisciplinary treatment.
Different interdisciplinary team models in diabetes management have been developed; including endocrinologists, dietitians, diabetes educators, mental health professionals, nurse practitioners, pharmacists, dentists, foot care professionals, physical activity trainers, and eye care professionals, among others ${ }^{2,3}$. 
In this report, $69.3 \%$ of the study population were overweight or obese and $77.1 \%$ had abdominal obesity. This information agrees with data from national health surveys conducted in Mexico, showing a combined prevalence of overweight and obesity in 2018 of $75.2 \%$ and a prevalence of abdominal obesity in 2016 of $76.6 \%{ }^{15}$. Although a high $\mathrm{HbA} 1 \mathrm{c}$ was one of the criteria to be included in the education sessions, the values of fasting glucose and $\mathrm{HbA} 1 \mathrm{C}$ observed in the participants are similar to data obtained in the Mexican population. It has been reported that only $31.8 \%$ of people living with diabetes in Mexico has a concentration of $\mathrm{HbA} 1 \mathrm{c}<7 \%{ }^{16}$.

Results concerning the variables related to diabetes education showed a deficiency in the patients' knowledge about their disease. Only $8.5 \%$ and $19.0 \%$ of the study population knew correctly the pre-prandial and post-prandial glucose targets, respectively; along with $48.5 \%$ of participants not practicing or not frequently performing SMBG. This contributes to the lack of glycemic control because lack of assessment of glucose concentrations daily, and in those who perform SMBG lack of knowledge regarding how to interpret the results. This reflects that actions to improve glycemic control, to avoid hyperglycemia and hypoglycemia episodes are not performed.

HbA1c showed a tendency to decrease $(-0.31 \%$ [95\% IC: $-0.64,0.01], p=0.06)$ and fasting and post-prandial $<2$ h capillary glucose concentrations were significantly lower at follow-up. Similar effects have been reported in other studies and populations. A meta-analysis evaluating the impact of diabetes education interventions showed a reduction of $0.76 \%$ of $\mathrm{HbA1c}$; however, after 4 months, the difference in $\mathrm{HbA} 1 \mathrm{c}$ was reduced to $0.26 \%^{8}$. A systematic review included 118 interventions of diabetes self-management education and support, showing that $61.9 \%$ reported significant changes in $\mathrm{HbA} 1 \mathrm{c}$ with an average reduction of $0.57 \%{ }^{9}$. Greater reductions in $\mathrm{HbA} 1 \mathrm{c}$ have been described in people with type 1 diabetes in comparison to people with type 2 diabetes ${ }^{17}$.

Patients attending the education sessions showed significant changes in components that promote self-management of their disease including knowing glycemic targets, performing an adequate insulin injection technique, and practicing SMBG. These findings favor that diabetes education should be included routinely in the integral care of patients with diabetes, promoting empowerment, and making informed and appropriate decisions.

Limitations of this report should be acknowledged, this is an observational retrospective study, and the results were obtained with an analysis of secondary data of a heterogeneous population. The group of health professionals delivering the education sessions is trained as diabetes educators; however, the procedures performed in each consultation were not fully standardized. The impact of the education sessions was evaluated in a small subset of participants with a diverse follow-up period. Although some positive changes were observed, the effect of a single consultation was evaluated. Therefore, a structured long-term program with scheduled appointments could generate a higher impact.

A systematic review concluded that structured education interventions promote positive changes on glucose control and hypoglycemia ${ }^{18}$. Furthermore, a contact $\geq 10 \mathrm{~h}$ and a combination of group and individual sessions are associated to a greater impact in glucose control ${ }^{9}$. Long-term randomized clinical trials with well-structured and standardized diabetes education interventions are needed in countries like Mexico. A study conducted in Mexican low-income patients with type 2 diabetes reported that some of the challenges to promote self-management are cultural beliefs, personal control, and low health litera$\mathrm{cy}^{19}$. According to the current worldwide evidence, it will be useful to implement effective diabetes education strategies that are more accessible to the general population at all levels of health care to reduce the incidence and progression of complications, mortality, and the costs derived from this disease.

\section{CONCLUSIONS}

The knowledge about diabetes in people living with it in Mexico is insufficient. Since a single session of diabetes education had a positive impact, interventions related to diabetes education could promote better adherence to self-care behaviors in patients 
with diabetes and should be implemented in other health institutions.

\section{FUNDING}

This research received a research grant from the Sociedad Mexicana de Nutrición y Endocrinología.

\section{CONFLICTS OF INTEREST}

The authors declare that they have no conflicts of interest.

\section{ETHICAL DISCLOSURES}

Protection of human and animal subjects. The authors declare that no experiments were performed on humans or animals for this study.

Confidentiality of data. The authors declare that they have followed the protocols of their work center on the publication of patient data.

Right to privacy and informed consent. The authors have obtained the informed consent of the patients and / or subjects referred to in the article.

\section{REFERENCES}

1. Świątoniowska N, Sarzyńska K, Szymańska-Chabowska A, JankowskaPolańska B. The role of education in Type 2 diabetes treatment. Diabetes Res Clin Pract. 2019;151:237-46.
2. McGill M, Blonde L, Chan JC, Khunti K, Lavalle FJ, Bailey CJ, et al. The interdisciplinary team in Type 2 diabetes management: challenges and best practice solutions from real-world scenarios. J Clin Transl Endocrinol. 2017:7:21-7.

3. Hernandez-Jimenez S, Garcia-Ulloa C, Mehta R, Aguilar-Salinas C, Kershenobich-Stalnikowitz D. Innovative models for the empowerment of patients with Type 2 diabetes: the CAIPaDi program. Recent Pat Endocr Metab Immune Drug Discov. 2014;8:202-9.

4. Association of Diabetes Care and Education Specialists. 7 Self-care Behaviors; 2019. Available from: https://www.diabeteseducator.org/living-with-diabetes/aade7-self-care-behaviors. [Last accessed on 2020 Sep 23]

5. Allen NA. The history of diabetes nursing, 1914-1936. Diabetes Educ. 2003;29:976-89.

6. King KM, Rubin G. A history of diabetes: from antiquity to discovering insulin. Br J Nurs 2003;12:1091-5.

7. American Diabetes Association. 3. Prevention or delay of Type 2 diabetes: standards of medical care in diabetes-2020. Diabetes Care. 2020;43:S32-6.

8. Norris SL, Lau J, Smith SJ, Schmid CH, Engelgau MM. Self-management education for adults with Type 2 diabetes. A meta-analysis of the effect on glycemic control. Diabetes Care. 2002;25:1159-71.

9. Chrvala CA, Sherr D, Lipman RD. Diabetes self-management education for adults with Type 2 diabetes mellitus: a systematic review of the effect on glycemic control. Patient Educ Couns. 2016;99:926-43.

10. Cochran J, Conn VS. Meta-analysis of quality of life outcomes following diabetes self-management training. Diabetes Educ. 2008;34: 815-23.

11. He X, Li J, Wang B, Yao Q, Li L, Song R, et al. Diabetes self-management education reduces risk of all-cause mortality in Type 2 diabetes patients: a systematic review and meta-analysis. Endocrine. 2017;55: 712-31.

12. Duncan I, Ahmed T, Li QE, Stetson B, Ruggiero L, Burton K, et al. Assessing the value of the diabetes educator. Diabetes Educ. 2011;37: 638-57.

13. American Diabetes Association. 6. Glycemic targets: standards of medical care in diabetes-2020. Diabetes Care. 2020;43:S66-76.

14. Powers MA, Bardsley J, Cypress M, Duker P, Funnell MM, Fischl AH et al. Diabetes self-management education and support in Type 2 diabetes: a joint position statement of the American diabetes association, the American association of diabetes educators, and the academy of nutrition and dietetics. Diabetes Care. 2015;38: 1372-82.

15. Secretaría de Salud de México, Instituto Nacional de Salud Pública, Instituto Nacional de Estadística y Geografía. Encuesta Nacional de Salud y Nutrición (ENSANUT) 2018. Mexico City; 2019. Available from: https:// www.ensanut.insp.mx/encuestas/ensanut2018/doctos/informes/ensanut 2018 presentacion resultados.pdf.

16. Basto-Abreu A, Barrientos-Gutiérrez T, Rojas-Martínez R, Aguilar-Salinas CA, López-Olmedo N, De la Cruz-Góngora V, et al. Prevalencia de diabetes y descontrol glucémico en México: resultados de la Ensanut 2016. Salud Publica Mex. 2020;62:50-9.

17. Koev DJ, Tankova TI, Kozlovski PG. Effect of structured group education on glycemic control and hypoglycemia in insulin-treated patients. Diabetes Care. 2003;26:251.

18. Yorke $E$, Atiase $Y$. Impact of structured education on glucose control and hypoglycaemia in Type-2 diabetes: a systematic review of randomized controlled trials. Ghana Med J. 2018;52:41-60.

19. Whittemore R, Vilar-Compte M, De La Cerda S, Marron D, Conover R, Delvy $\mathrm{R}$, et al. Challenges to diabetes self-management for adults with Type 2 diabetes in low-resource settings in Mexico city: a qualitative descriptive study. Int J Equity Health. 2019;18:133. 